Figures appearing in the EDITOR'S CHOICE are those arising from materials research which strike the editor's fancy as being aesthetically appealing and eye-catching. No further criteria are applied and none should be assumed. When taken out of context, such figures often evoke images beyond and unrelated to the original meaning. Submissions of candidate figures are welcome and should include a complete source citation, a photocopy of the report in which it appears (or will appear), and a reproduction-quality original drawing or photograph of the figure in question.

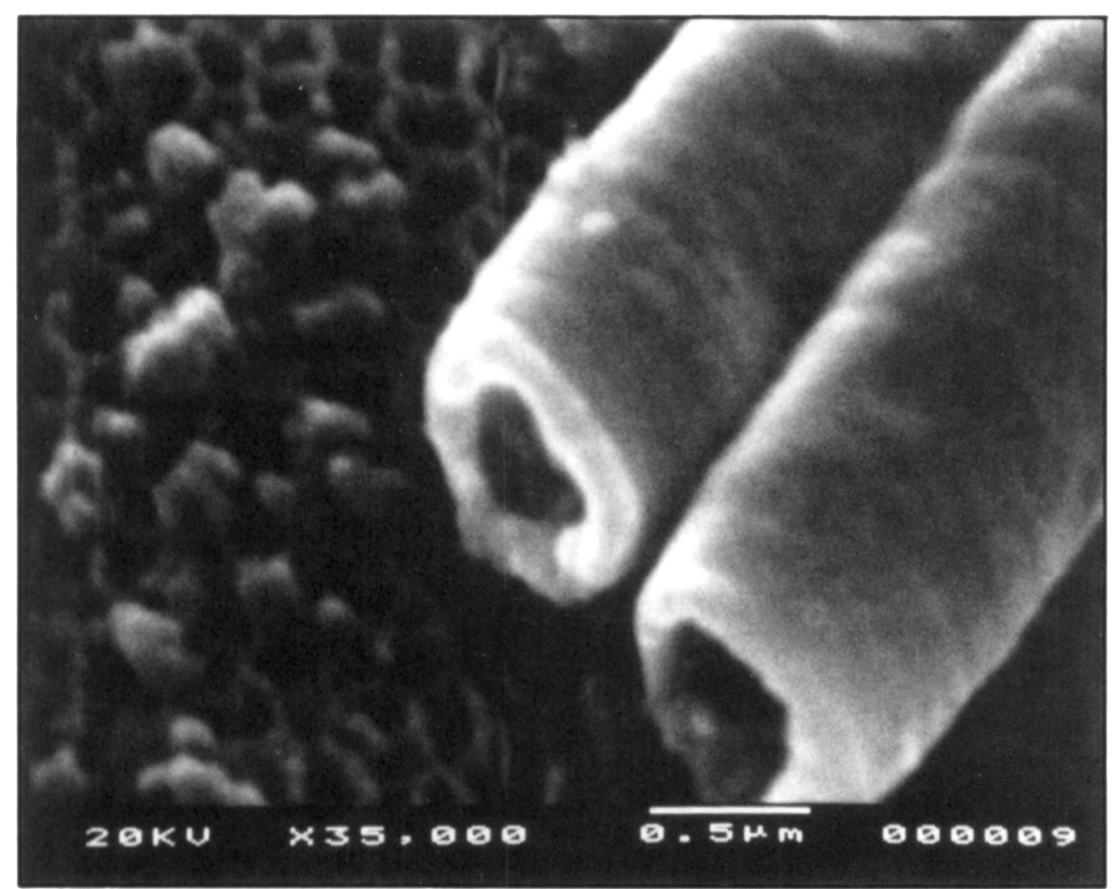

Not available yet in the plumbing-supply section of your local hardware store, this variety of polymer-based piping might not measure up to required household flow rates anyway. These half-micron diameter, eight-micron long microtubules were synthesized using a new "templating" method by C.R. Martin, L.S. Van Dyke, Z. Cai, and W. Liang of Colorado State University's Chemistry Department U. Am. Chem. Soc. 112 (1990) p. 8976]. They are polypyrroles formed on the inner walls of a microporous membrane which separated a pyrrole monomer solution from a polymerization agent. Although plumbing may be a pipe dream at these dimensions, novel applications in electronics and biomedical areas are likely.

Editor's Choice candidates are being accepted for the 1992 MRS Bulletin. Send your contributions to: Editor, MRS Bulletin, Materials Research Society, 9800 McKnight Road, Pittsburgh, PA 15237.

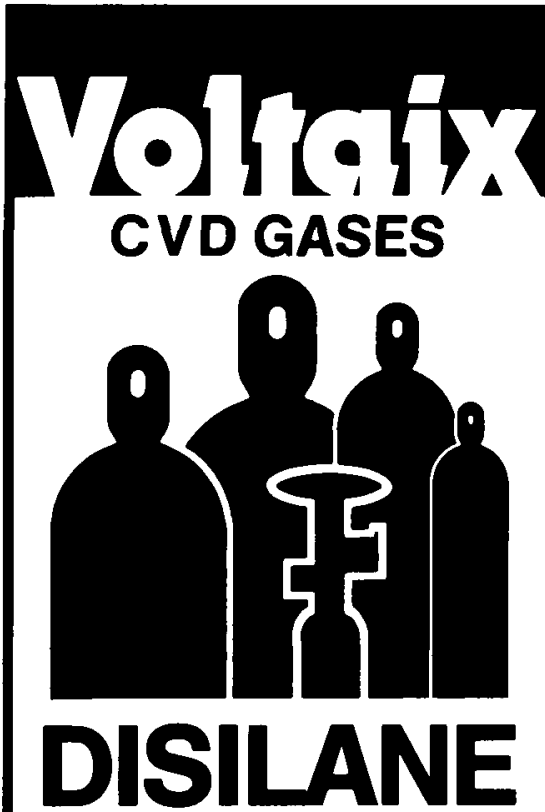

Highest Purity Available, Anywhere (1500 ohm-cm)

\section{Quality Control}

- 100\% GC / MS analysis

\section{Packaging Options}

- Any quantity, same spec.

- Steel, polished steel or aluminum cylinders

- Pneumatic valves for fail-safe gas supply

- Optional flow restrictor for added safety

- "Keyed" VCR outlet for UHV connection to system

\section{Also of Interest}

- Diborane

- Trimethylboron

- Germane

- Digermane

- All mixtures

\section{Voltaix, Inc.}

P.O. Box 5357, 197 Meister Ave.

N. Branch, New Jersey 08876

Telephone: (908) 231-9060

Facsimile: (908) 231-9063 